\title{
pH-Dependent Ion Binding Studies on 2-Mercaptopyrimidine
}

\author{
Kamara $\mathrm{B}^{1^{*}}$, Kamara $\mathrm{HM}^{1}$ and Phambu $\mathrm{N}^{2}$
}

${ }^{1}$ Department of Chemistry, Morgan State University, Baltimore, Maryland, USA

${ }^{2}$ Department of Chemistry, Tennessee State University, Nashville, Tennessee, USA

${ }^{*}$ Corresponding author: Kamara B, Department of Chemistry, Morgan State University, Baltimore, Maryland, USA, Tel: +443-885-3794; E-mail: beebeekamara@gmail.com

Received date: August 03, 2018; Accepted date: August 12, 2018; Published date: August 15, 2018

Copyright: $\odot 2018$ Kamara B, et al. This is an open-access article distributed under the terms of the Creative Commons Attribution License, which permits unrestricted use, distribution, and reproduction in any medium, provided the original author and source are credited.

\begin{abstract}
Mercaptopyrimidines exhibit antiviral and antibacterial properties and were found to inhibit the synthesis of tRNA thus acting as antitumor and antithyroid agents. These molecules exhibit tautomeric equilibrium between the thiol and thione because of the highly mobile protons they possess. These compounds can incorporate metal ions in their structure because they possess electron donor atoms. Metal ions are electron acceptor species; they come from food, medicine, and drinking water. The objective of this project was to investigate whether and how metal ions such as $\mathrm{Na}^{+}, \mathrm{Hg}^{2+}, \mathrm{Al}^{3+}, \mathrm{Ce}^{4+}$, and $\mathrm{UO}^{22+}$ affect the structure of 2-mercapto pyrimidine using electronic and Vibrational spectroscopes. Binding studies were conducted in aqueous solutions at different $\mathrm{pH}$ and metal ion/ligand molar ratios. It is hypothesized that interaction does occur between metal ions of valence other than two and certain numbers of 2-Mercaptopyrimidine. However, the interactions tend to differ from one metal ion to another depending on the charge of the metal ion.

The electronic spectra have shown, the $\mathrm{pH}$ affects the structure of $2 \mathrm{MCP}$, the thione form is the dominant species in water, and all the metal ions cited above interact with a 2-mercapto pyrimidine. $\mathrm{But}_{\mathrm{Hg}^{2+}}$ and $\mathrm{Ce}^{4+}$ interact with 2mercapto pyrimidine more strongly than $\mathrm{Na}^{+}, \mathrm{Al}^{3+}$, and $\mathrm{UO}^{22+}$. The stability constant calculated using electronic spectra and a Scatchard plot demonstrated that the complexes of $\mathrm{Hg}$ and $\mathrm{Ce}$ with 2-mercapto pyrimidine are the most stable.
\end{abstract}

Keywords: Analytical chemistry; Biochemistry; Antioxidant activities; Antibacterial activities; Spectroscopy

\section{Introduction}

Metal ions come from food, medicine and drinking water [1]. An understanding of their role in the biological systems has become essential to the practice of medicine. The presence of metal ions has been associated with the misfolding process of proteins and structural change in DNA, leading to some types of cancers, and neurodegenerative diseases [2,3]. Metal ions released by antacid preparations resulted in a nearly complete loss of activity of antibacterial $[3,4]$. So it is mandatory that the effect of metal ions on the structure (thus on the activity) of some pharmaceuticals be investigated. There is a need to better understand potential metal ionpharmaceuticals interactions in order to reduce possible adverse effects or enhance the efficacy of the drugs being employed and to better inform patients [5-10]. The chemistry of mercapto pyrimidines is attracting research interest because it involves both $\mathrm{S}$ and $\mathrm{N}$ atoms in their structures $[10,11]$. There is a considerable versatility in the coordination modes of these molecules, which may include monodentate binding through $\mathrm{S}$ or through $\mathrm{N}$, bridging through a single $\mathrm{S}$, and bridging through both $\mathrm{S}$ and $\mathrm{N}$ or chelating via $\mathrm{S}$ to $\mathrm{N}$ backbone. In other terms, these compounds can coordinate as monodentate ligands and more frequently as polydentate ligands either to a single metal center, acting as a chelating ligand, or to several metal centers as bridging ligand. In addition, these compounds exhibit a tautomeric equilibrium between the $>\mathrm{C}$-SH (thiol) and the $>\mathrm{C}=\mathrm{S}$ (thione) form due to the highly polar protons they possess (Figure 1).
The predominant form largely depends on the state and conditions of the molecule [11]. However, in the solution phase, there are several factors influencing the tautomeric equilibrium. Among the most prominent are the solvent, temperature, $\mathrm{pH}$, and concentration. Thus, it was suggested that the thione form predominates over the thiol form in a polar solvent; while the thiol form predominates in a polar solvent.

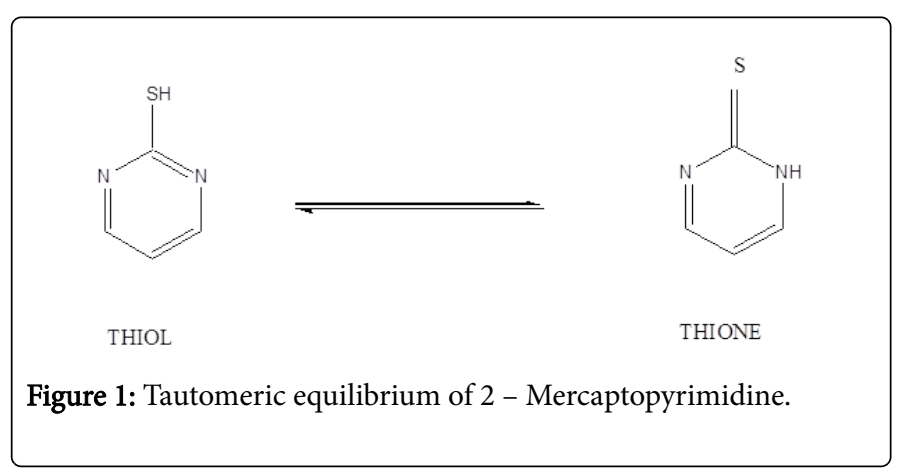

The Pharmaceutical drug 2-mercapto pyrimidine is the thione form. The sulfur atom in the thione attacked the excess iodine on people that have thyroid diseases. Therefore, it is very important for the availability of the sulfur atom in the thione form of 2-mercapto pyrimidine.

Among these mercapto pyrimidine compounds, we have chosen to focus on 2-mercapto pyrimidine (2-MCP). This drug is used in the treatment of Hashimoto's thyroiditis and Grave's disease, which are the two most common autoimmune thyroid disorders [6]. Although antithyroid drugs have been used for over 50 years, their mechanisms of 
Page 2 of 11

action are still poorly understood at the molecular level. 2MCP also exhibits antiviral, antibacterial and anti-tumor properties.

To our knowledge, there are only a few experimental papers concerning the tautomerism of 2MCP. The energies of the two tautomers in polar and non-polar solvents were calculated using Density Functional Theory (DFT). The results indicated that thiol structure is the most stable species, but the energy values become very close to each other once a solvent such as cyclohexane was included. This result points to the coexistence of the two species of the tautomeric equilibrium $[6,11]$.

Interactions of $2 \mathrm{MCP}$ with divalent heavy metal ions such as mercury have been extensively investigated, probably because both heterocyclic thiones and thionate are among the system used to mimic bio-relevant $\mathrm{Hg}$-S interactions (Cysteinyl sulfur residues in a variety of bio-systems). There is a lack of data regarding the interaction between 2MCP and metal ions of valence other than two. There is also some disagreement on the coordination modes of 2MCP: both $\mathrm{N}$ and $\mathrm{S}$ coordination was suggested earlier for some complexes; other publications suggested that coordination is via exocyclic sulfur only [10-12]. The objective of this project was to investigate whether and how metal ions such as $\mathrm{Na}^{+}, \mathrm{Hg}^{2+}, \mathrm{Al}^{3+}, \mathrm{Ce}^{4+}$ and $\mathrm{UO}^{22+}$ affect the structure of 2-mercapto pyrimidine using electronic and vibration spectroscopes. The binding studies were conducted in aqueous solution at different $\mathrm{pHs}$ and metal ion/2MCP ratios. It was hypothesized that significant interaction does occur between metal ions of valence other than two and certain members of $2 \mathrm{MCP}$. The extent of interaction will vary from one metal ion to another depending on the charge of the metal ion. The mechanism of reaction may be attributed to chelation. The specific goals of this research are: To investigate the interaction between $2 \mathrm{MCP}$ and metal ions cited above using UV visible and fluorescence spectra. This was to estimate the binding affinity of $2 \mathrm{MCP}$ towards each metal ion. To determine the binding stability constants for the metal ion-2MCP complex using electronic spectra. To determine the mechanisms of interaction between $2 \mathrm{MCP}$ and the selected metal ions using infrared and Raman spectra. The objective is to identify the preferred binding sites of metal ions on 2MCP. The techniques employed here are useful in probing the structural changes upon complexation. This project will provide new insights on a number of drugs and potential pharmaceutical agents containing metal-binding or metal-recognition sites that can bind or interact with metal ions and potentially influence their bioactivities and might also cause damages on their target biomolecules. These studies have great potential to improve the fundamental understanding of thiones/thiols, as well as biological catalysis in general. In addition, since the design of bioactive thione/thiol derivatives for pharmaceutical applications depend on an adequate understanding of catalytic mechanism; this research may significantly advance thiones toward their potential as therapeutics for several devastating diseases, including AIDS, cancer, and hepatitis C. Finally, the development of highly efficient and specific heavy metal sequestering thione could, ultimately, provide a viable and biodegradable means of removing heavy metals from contaminated water. Tautomerism is an important aspect of several chemical and biological processes. Among all possible solvents, water is the natural biological solvent and is involved with all processes related to life. Investigation of the tautomeric reactions in an aqueous environment is a great theoretical challenge, and this is the basis for this research.

\section{Materials and Methods}

\section{Materials: Reagents, $\mathrm{pH}$, and metal/ligand molar ratio}

All chemicals were of analytical-reagent grade. All aqueous solutions are prepared with deionized water that is further purified by a Millipore Milli-Q high purity water device (Milli-Q-System A10 from Waters, Millipore, and Billerica, MD). 2-Mercaptopyrimidine, metal salts (as chloride salts) and all other reagents (Cerium sulfate and uranyl acetate hydrates) were commercially obtained and used as received from Fisher. Solution $\mathrm{pH}$ was adjusted using concentrated $\mathrm{HCl}(\mathrm{aq})$ or $\mathrm{NaOH}(\mathrm{aq})$ to give $\mathrm{pH}$ ranging from 1-9. The interaction experiments were done using aqueous solutions at room temperature. For each experiment at the desired $\mathrm{pH}$, the metal/ligand molar ratios used are 0.5 (excess 2MCP), 1 (equimolar), and 2 (excess metal ion).

\section{Methods}

Aqueous solutions were prepared to take into account the molar mass of $2 \mathrm{MCP}$ and of ion salts, and the metal ion/ligand molar ratio. After interaction between the aqueous metal ion solution and $2 \mathrm{MCP}$, two experiments were conducted: (a) the resulting complexes were directly analyzed by UV visible in solution [12]; (b) the resulting complexes were filtered, dried and then analyzed as solids by infrared and Raman spectroscopies [13]. Table 1 Summarizes the calculated masses of $2 \mathrm{MCP}$ and the above metal ions at $10^{-4} \mathrm{M}$ and $10^{-3} \mathrm{M}$ concentrations.

\begin{tabular}{|c|c|c|c|}
\hline Compound & Metal ion & Mass at Conc. $\mathbf{1 0}^{-4} \mathbf{M}$ & Mass at Conc. $\mathbf{0}^{-3} \mathbf{M}$ \\
\hline 2-MCP & & $0.00112 \mathrm{~g}$ & $0.0112 \mathrm{~g}$ \\
\hline & $\mathrm{NaCl}$ & $0.0006 \mathrm{~g}$ & $0.006 \mathrm{~g}$ \\
\hline & $\mathrm{HgCl}_{2}$ & $0.0027 \mathrm{~g}$ & $0.0270 \mathrm{~g}$ \\
\hline & $\mathrm{AlCl}_{3}$ & $0.0024 \mathrm{~g}$ & $0.0240 \mathrm{~g}$ \\
\hline & $\mathrm{CeSO}_{4}$ & $0.0033 \mathrm{~g}$ & $0.0330 \mathrm{~g}$ \\
\hline & $\mathrm{UO}^{22+}$ & $0.0043 \mathrm{~g}$ & $0.043 \mathrm{~g}$ \\
\hline
\end{tabular}

Table 1: Calculated masses of 2MCP and metal ions.

\section{Characterization methods}

UV visible spectroscopy: The samples for absorption measurements were placed in a quartz cell of path length $1 \mathrm{~cm}$. UV visible spectra were obtained using a Varian CARY BIO 300 spectrometer, using a sample of deionized water as the reference. The absorbance spectra were recorded between $800 \mathrm{~nm}$ and $200 \mathrm{~nm}$.

UV visible spectroscopy is a powerful tool for studying the structure of $2 \mathrm{MCP}$ and its metal complexes in aqueous solution. Transmission comes from the $\pi$ and $n$ electrons of the aromatic ring [12,14].

Infrared and Raman spectroscopes: Infrared spectra of the sample were obtained using Perkin Elmer FTIR Spectrum One spectrometer using pure samples. The spectra were recorded between 4000 and 600 $\mathrm{cm}^{-1}$. Spectra were obtained by integrating scans at a resolution of 4 $\mathrm{cm}^{-1}[15,16]$. The infrared spectra were obtained using an attenuated total reflectance (ATR) device. The spectra shown are the difference spectra obtained by using the subtraction routine between the spectrum of the reference and the spectrum of the sample [13]. Ambient air was used for the background or reference. 
Raman spectra were taken on a HORIBA Jobin Yvon FT-Raman using pure samples. The spectra were recorded between $4000 \mathrm{~cm}^{-1}$ and $0 \mathrm{~cm}^{-1}$ at $4 \mathrm{~cm}^{-1}$ resolutions. A 633 laser was used as an excitation line. The detector was a liquid nitrogen cooled Ge detector. The output laser power was set to $50 \mathrm{~mW}$.

FT-IR and Raman were used to study the structure of $2 \mathrm{MCP}$ and its metal complexes as powders. The $\mathrm{C}=\mathrm{S}$ and $\mathrm{N}-\mathrm{H}$ groups give rise to well-known stretching and bending in the electromagnetic spectrum. Raman spectroscopy has been used extensively for the study of active sites of metalloproteins. Structural and bonding information has been gained especially because the metal-ligand vibrations are found below $1000 \mathrm{~cm}^{-1}$ in the Raman spectra. Typically, the Raman spectrum of the $2 \mathrm{MCP}$ will display an additional peak (compared to the metal-free 2MCP Raman spectrum) in this region upon metal complexation. This peak at low frequency is characteristic of metal-2MCP interaction [13].

\section{Results}

\section{Electronic spectra}

First, the UV-visible spectrum of metal-free $2 \mathrm{MCP}$ was recorded alone, second record the UV visible of $2 \mathrm{MCP}$ after interaction with a selected metal ion, and third, the absorbances were compared. If the two absorbances have the same value, there is no interaction; if they are different, there is interaction. Interpretation of UV visible spectra is based on electronic data found in the literature [13,15-19].

\section{Effect of solvent on the structure of $2 \mathrm{MCP}$}

To identify the predominant tautomer of $2 \mathrm{MCP}$ in water as solvent relative to other nonpolar solvents. Figures 2 and 3 show the UV visible spectra of metal-free 2-mercapto pyrimidine in water and cyclohexane, respectively. The electronic spectra of $2 \mathrm{MCP}$ in water exhibited three bands at $212 \mathrm{~nm}, 278 \mathrm{~nm}$, and $344 \mathrm{~nm}$ and changed substantially when cyclohexane was used as the solvent $[12,14]$. In the latter case, a major band at $238 \mathrm{~nm}$ and two weaker bonds at $213 \mathrm{~nm}$ and $275 \mathrm{~nm}$ were clearly distinguished. As documented in the literature, bands at 212 $\mathrm{nm}, 278 \mathrm{~nm}$, and $344 \mathrm{~nm}$ correspond to the thione form while the band at $238 \mathrm{~nm}$ corresponds to the thiol form. These observations demonstrate that the tautomeric thione structure is favored in polar solvents, while the thiol structure dominates in non-polar media, in agreement with the literature.

Bands at $212 \mathrm{~nm}, 278 \mathrm{~nm}$, and $344 \mathrm{~nm}$ are due to $2 \mathrm{MCP}$ in water so will follow the change in frequency or intensity of these bands when adding metal ions to $2 \mathrm{MCP}$.

\section{Effect of $\mathrm{pH}$ on the electronic spectra of metal-free 2- mercapto pyrimidine}

The importance of $\mathrm{pH}$ : There is a dramatic effect of $\mathrm{pH}$ on the structure of 2-mercapto pyrimidine. Figure 4 shows the UV visible

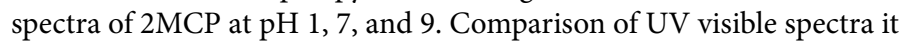
shows that $\mathrm{pH}$ has a significant effect on the peak positions of $2 \mathrm{MCP}$. Our reference is the spectrum of $2 \mathrm{MCP}$ at $\mathrm{pH}$ 7. The peaks are 212 , 278 , and $344 \mathrm{~nm}$. When the $\mathrm{pH}$ was adjusted to 9 (alkaline solution), the peak at 278 shifts to a lower wavelength $(265 \mathrm{~nm})$ and decreases in intensity; the peak at $212 \mathrm{~nm}$ shifts to $225 \mathrm{~nm}$ and decrease in intensity. The peak at $344 \mathrm{~nm}$ disappeared. When the $\mathrm{pH}$ was adjusted to 2 (acidic solution), the peak at 278 shifts to a higher wavelength ( 285 $\mathrm{nm}$ ) and increases in intensity; and the peak at $212 \mathrm{~nm}$ shifts slightly to
$215 \mathrm{~nm}$ and increases in intensity. The peak at $344 \mathrm{~nm}$ shifts to $350 \mathrm{~nm}$ with no change in intensity.

The structure of $2 \mathrm{MCP}$ is seriously affected by the changes in $\mathrm{pH}$. An acidic solution favors the protonation of $2 \mathrm{MCP}$ and an alkaline solution favors deprotonation of $2 \mathrm{MCP}$. The effects of $\mathrm{pH}$ in both acidic and alkaline mediums changed the structure of $2 \mathrm{MCP}$.

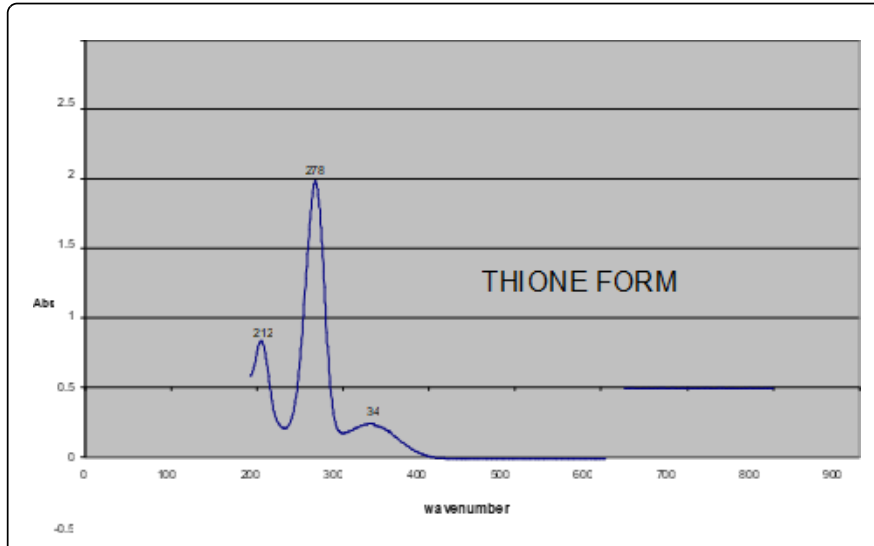

Figure 2: $2 \mathrm{MCP}$ in water (polar solvent).

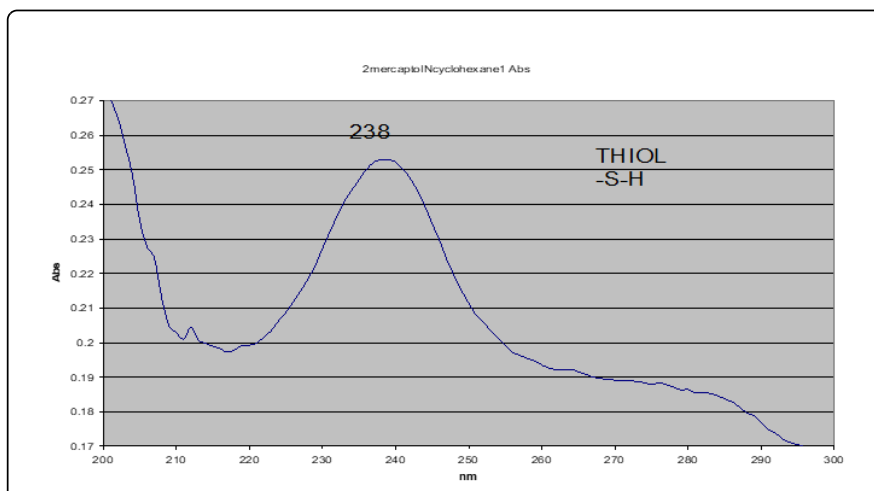

Figure 3: $2 \mathrm{MCP}$ in Cyclohexane (nonpolar solvent).

\section{Effect of complexation on the structure of 2- Mercaptopyrimidine}

To estimate the binding capacity of $2 \mathrm{MCP}$ toward selected metal ions (goal\#1).

Absorbance measurements were carried out at different $\mathrm{pH}$ values and metal ion/2MCP molar ratios. In all the cases, the Beer Lamber law was verified, which states:

The absorbance was proportional to the amount of $2 \mathrm{MCP}$.

$$
\mathrm{A}=\varepsilon \mathrm{cl}
$$

Where $\mathrm{A}=$ Absorbance,

$\mathrm{l}=$ path length $(\mathrm{cm})$,

$c=$ Concentration,

$\varepsilon=$ Molar absorptivity. 
Therefore, absorbance is proportional to the concentration of the sample of 2MCP, (A a C) Figure 5 shows the absorbance spectra of $2 \mathrm{MCP}$ in the absence and presence of $\mathrm{Ce}^{4+}$ ions. $2 \mathrm{MCP}$ has strong absorbance with peaks at $212 \mathrm{~nm}, 284 \mathrm{~nm}$, and $350 \mathrm{~nm}$ at $\mathrm{pH} 1$. Its absorbance intensity at $284 \mathrm{~nm}$ decreases with increasing concentration of cerium ions, indicating binding of cerium ions to $2 \mathrm{MCP}$.

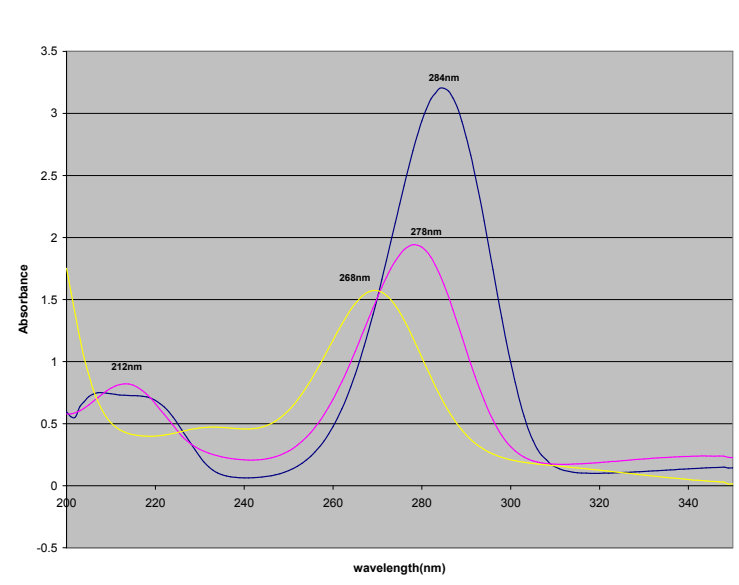

Figure 4: Comparison of UV-Visible spectra of $2 \mathrm{MCP}$ at $\mathrm{pH} 1,7$, and 9.
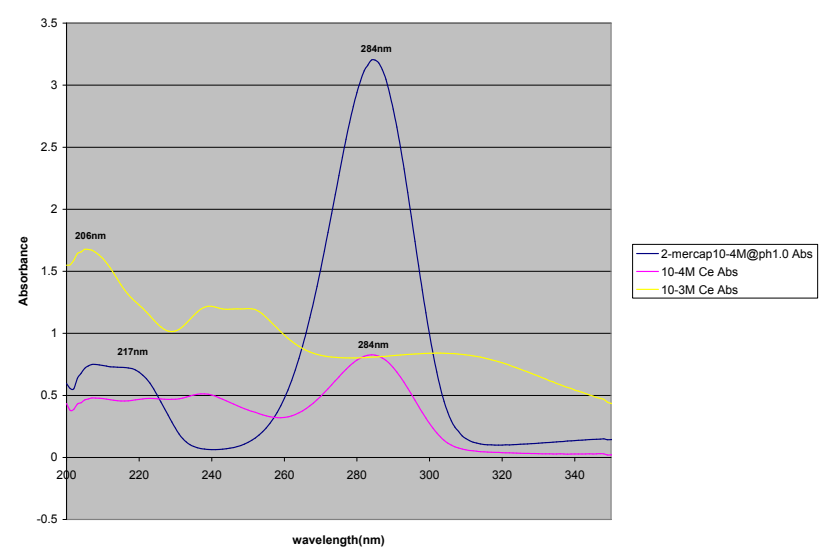

Figure 5: Comparison of UV-Visible spectra of $2 \mathrm{MCP}$ after interaction with Ce (IV).

Figure 6 shows the comparison of UV-Visible spectra of $2 \mathrm{MCP}$ interacting with $\mathrm{Hg}^{2+}$ at concentration $10^{-4} \mathrm{M}$. 2MCP shows stronger absorbance with peak intensities of $212 \mathrm{~nm}, 284 \mathrm{~nm}$ at $\mathrm{pH}$. The absorbance of $2 \mathrm{MCP}$ decreases when $\mathrm{Hg}^{2+}$ ions concentration was added, which explains the binding of $\mathrm{Hg}^{2+}$ to $2 \mathrm{MCP}$.

The same approach was used for Figures 7-9, (i.e., $\mathrm{Na}^{+}, \mathrm{Al}^{3+}$, and $\mathrm{UO}^{22+}$ ) ions interacting with $2 \mathrm{MCP}$. The $2 \mathrm{MCP}$ has strong absorbance, but when the metal ions were added, they show less binding or interaction with $2 \mathrm{MCP}$.

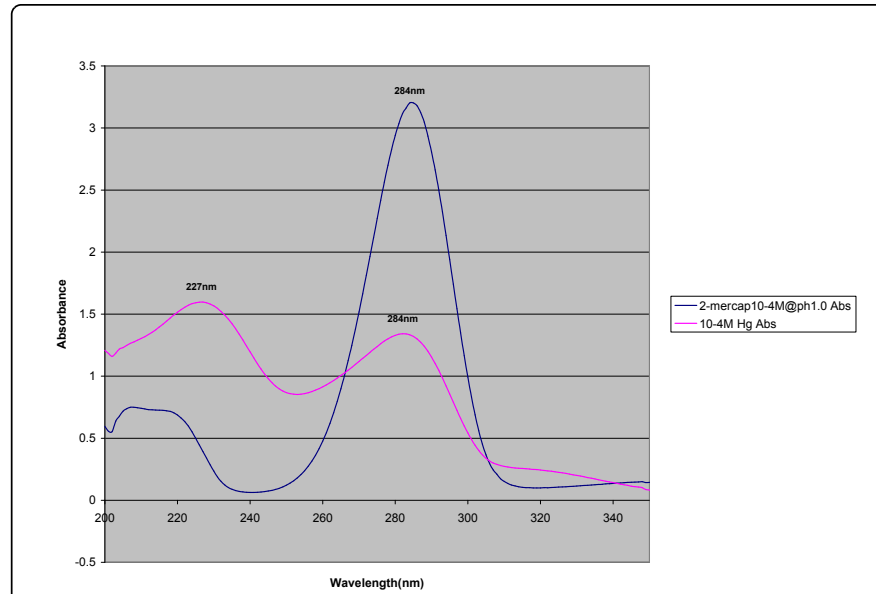

Figure 6: Comparison of UV-Visible Spectra of $2 \mathrm{MCP}$ after interacting with $\mathrm{Hg}$ (II).

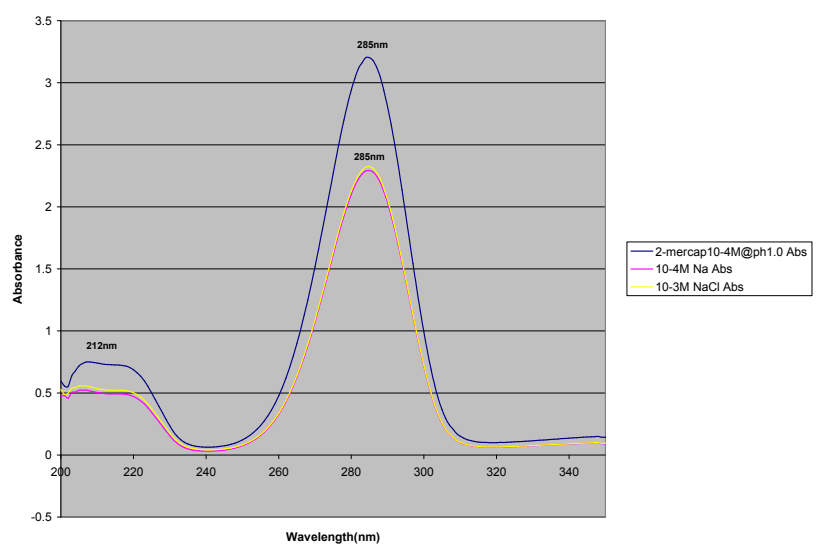

Figure 7: Comparison of UV-Visible Spectra of $2 \mathrm{MCP}$ after interacting with $\mathrm{Na}(\mathrm{I})$.

The absorbance measurements presented in this section were done to verify the binding capacity of $2 \mathrm{MCP}$ towards selected metal ions. In other terms, we need to know which metal ion a higher binding affinity for $2 \mathrm{MCP}$ has when everything is equal. The concentration of $10^{-4} \mathrm{M}$ for $2 \mathrm{MCP}$ was chosen because the UV visible spectrum was good, so it was possible to exploit the absorbance at this concentration. The peak at $280 \mathrm{~nm}$ is the reference peak because this peak is the strongest. $\mathrm{pH} 1$ was selected because it is the $\mathrm{pH}$ we obtained the largest changes in absorbance. Then two solutions were prepared each containing $10^{-4} \mathrm{M}$ of $2 \mathrm{MCP}$. The first solution to $2 \mathrm{MCP}$ alone was the control. Another $10^{-4} \mathrm{M}$ of aluminum ions was added in the second solution. That means we use the metal ion/2MCP molar ratio 1 . The absorbance (peak at $280 \mathrm{~nm}$ ) of $2 \mathrm{MCP}$ of the two solutions were measured and compared. The difference between the two absorbance values corresponds to the number of metal ions interacting with $2 \mathrm{MCP}$. This difference over the absorbance of the control gave the percentage of the amount reacting with $2 \mathrm{MCP}$. Figure 10 summarizes the results obtained with all the metal ions interacting with $2 \mathrm{MCP}$ at $\mathrm{pH} 1,7$, and 
Page 5 of 11

9. Table 2 summarizes the results obtained with all the metal ions interacting with $2 \mathrm{MCP}$ at $\mathrm{pH} 1$ only.
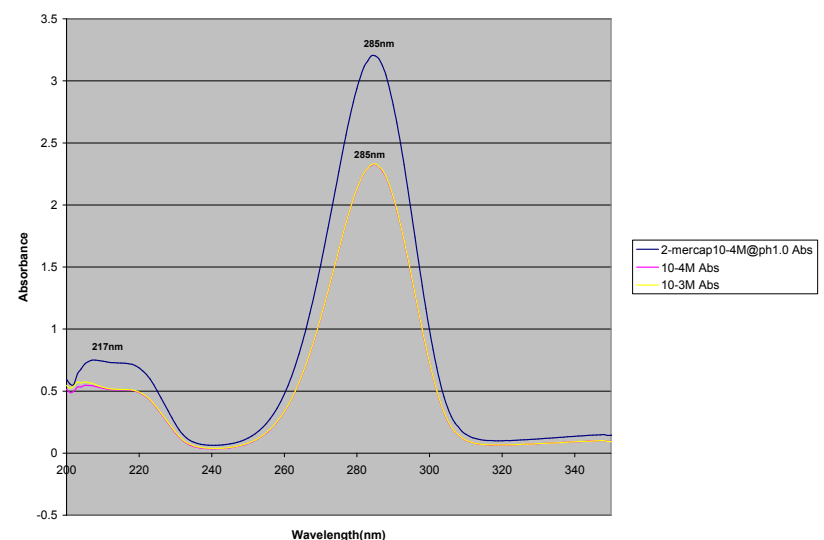

Figure 8: Comparison of UV-Visible Spectra of 2MCP after interacting with $\mathrm{Al}$ (III).

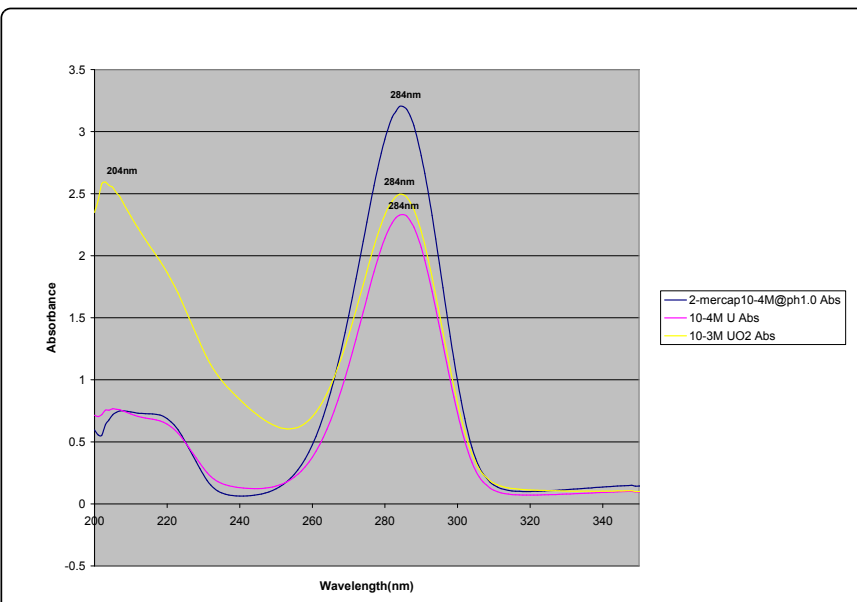

Figure 9: Comparison of UV-Visible Spectra of $2 \mathrm{MCP}$ after interacting with $\mathrm{U}(\mathrm{VI})$.

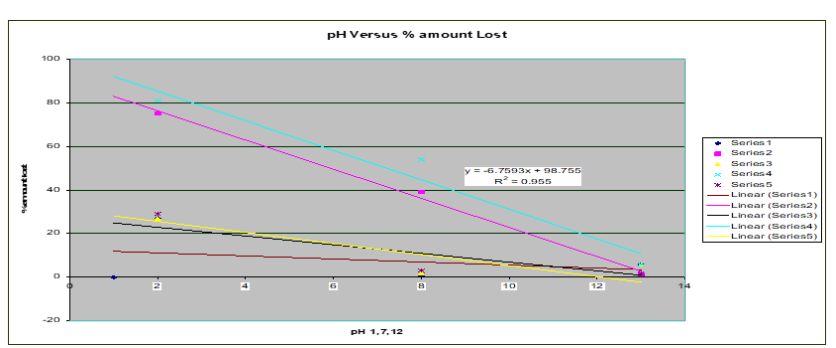

Figure 10: Comparison of $\mathrm{pH}$ profile, UV-Visible spectra of 2Mercaptopyrimidine before and after interaction with $\mathrm{Na}(\mathrm{I}), \mathrm{Hg}$ (II), $\mathrm{Al}$ (III), Ce (IV), and U (VI) metal ions.

Oxidation Number $10^{-4} \mathrm{M}$

$\%$ amount interacting with 2-MCP

\begin{tabular}{|c|c|}
\hline $\mathrm{Na}(\mathrm{I}):+1$ & 0.14 \\
\hline $\mathrm{Hg}(\mathrm{II}):+2$ & 0.81 \\
\hline $\mathrm{Al}(\mathrm{III}):+3$ & 0.27 \\
\hline $\mathrm{Ce}(\mathrm{IV}):+4$ & 0.75 \\
\hline $\mathrm{UO}^{26+}:+6$ & 0.29 \\
\hline
\end{tabular}

Table 2: Oxidation Number Versus \% amount lost at $\mathrm{pH} 1.0$ (Concentration $10^{-4} \mathrm{M} 2-\mathrm{MCP}$ ).

Results were clearly mentioned; the best results were obtained with $\mathrm{Hg}$ (II) and Ce (IV). Figure 10 summarizes the results obtained with all the metal ions interacting with $2 \mathrm{MCP}$ as a function of the oxidation states of the metal. The metal ions with the valence numbers 2 and 4 interact better with $2 \mathrm{MCP}$ than those with the oxidation states 1,3 , and 6 . The small amount of uranyl ion absorbed may be due to the presence of oxygen atoms in the uranyl compound.

\section{Calculations of stability constants (goal \# 2)}

To estimate the relative stability of the metal complexes of 2 MCP.

Based on the results obtained in the section above, we decided to investigate how stable the complexes formed between $2 \mathrm{MCP}$ and the metal ions are. In the literature, potentiometric titration and other electrochemical techniques have been used to estimate these constants for compounds other than $2 \mathrm{MCP}$. We decided to use a Scatchard plot using the data obtained using electronic spectra [20].

The equilibrium between a metal ion (M) and ligand (L) in solution yielding the product $(\mathrm{ML})$ can be described as follow: In general terms, the equilibrium constant $\mathrm{K}$ can be calculated as follows:

$$
\mathrm{Keq}=[\mathrm{ML}] /[\mathrm{M}][\mathrm{L}]
$$

$\mathrm{K}$ is also called the stability constant (expressed as a logarithm); [M] is the concentration of metal ion, and [L] is the concentration of a ligand 2MCP. The concentrations of $\mathrm{M}$ and of the complex ML are determined by measuring the absorbance of the appropriate solutions using UV visible spectroscopy. From equation 2 above other equations have been developed to obtain equations such as the Stern-Volmer or Scatchard equations widely used in biochemistry to measure the equilibrium constants. One of these equations has the following form: The Stern-Volmer equation;

$$
\mathrm{Ao} /(\mathrm{Ao}-\mathrm{A})=1 /(\mathrm{fK}[\mathrm{M}])+1 / \mathrm{f}
$$

Where $\mathrm{A}$ and $\mathrm{A}_{\mathrm{o}}$ are current $2 \mathrm{MCP}+$ metal ion and initial (2MCP reference) absorbance, respectively; $\mathrm{K}$ is the stability constant, $\mathrm{M}$ the concentration of metal ion, and $\mathrm{f}$ the fraction of the absorbance which is accessible to the metal ion. Because all the $2 \mathrm{MCP}$ is accessible to metal ions, $\mathrm{f}=1$.

The idea was to prepare a series of at least 4 solutions in which increments of $\mathrm{M}$ are added to a constant amount of $\mathrm{L}$. A series of solutions were prepared with a fixed concentration $\left(200 \mathrm{~mL}\right.$ of $10^{-4} \mathrm{M}$ $2 \mathrm{MCP})$ and various amounts of selected metal ions in water. The fixed concentration $\left(10^{-4} \mathrm{M}\right)$ of $2 \mathrm{MCP}$ is used as an internal reference; the measured absorbance is $A_{o}=2.395$ at $278 \mathrm{~nm}$. The absorbance of the solutions of $2 \mathrm{MCP}$ containing metal ions was then recorded and listed as $\mathrm{A}$. The average data of triplicate, independent results were used for the following discussion. For illustration, we give the example of calculation of the stability constant for an Al-2MCP complex (Figure 
Citation: Kamara B, Kamara HM, Phambu N (2018) pH-Dependent lon Binding Studies on 2-Mercaptopyrimidine. J Environ Anal Chem 5: 245. doi:10.4172/2380-2391.1000245

Page 6 of 11

7). The results for all the metal/2MCP complexes are shown in Table 3. As a table, the table will show, the stability constants are very low for the complex of $2 \mathrm{MCP}$ with $\mathrm{Na}$, intermediate for the complexes of
2MCP with aluminum and uranyl, and higher for the complex of cerium and mercury. These results are consistent with the data shown in Figure 10.

\begin{tabular}{|c|c|c|c|c|c|c|c|}
\hline $\operatorname{MCP}\left(10^{-4} \mathrm{M}\right)$ & & Mass (g) & \# mol/L & $\mathbf{A}_{0} / \mathbf{A}_{0}-\mathbf{A}$ & Slope & K & $\log K$ \\
\hline \multirow{30}{*}{$A_{\circ}$} & $\mathrm{NaCl}$ & 0 & 0 & & & & \\
\hline & & 8 & 0.685 & 356 & & & \\
\hline & & 15 & 1.285 & 294 & & & \\
\hline & & 22 & 1.88 & 171 & & & \\
\hline & & 26 & 2.225 & 137 & & & \\
\hline & & & & & 0.0065 & 154 & 2.187 \\
\hline & $\mathrm{HgCl}_{2}$ & 0 & 0 & & & & \\
\hline & & 0.01 & 0.0002 & 4.829 & & & \\
\hline & & 0.05 & 0.0009 & 3.496 & & & \\
\hline & & 0.1 & 0.002 & 1.781 & & & \\
\hline & & 0.15 & 0.003 & 1.201 & & & \\
\hline & & & & & 0.0005 & 2000 & 3.301 \\
\hline & $\mathrm{AlCl}_{3}$ & 0 & 0 & & & & \\
\hline & & 5 & 0.1035 & 88.704 & & & \\
\hline & & 10 & 0.207 & 70.112 & & & \\
\hline & & 15 & 0.311 & 38.629 & & & \\
\hline & & 20 & 0.4145 & 15.665 & & & \\
\hline & & & & & 0.004 & 250 & 2.398 \\
\hline & $\mathrm{Ce}\left(\mathrm{SO}_{4}\right)_{2}$ & 0 & 0 & & & & \\
\hline & & 0.1 & 0.0015 & 9.4 & & & \\
\hline & & 0.5 & 0.0075 & 7.2 & & & \\
\hline & & 0.8 & 0.012 & 3.5 & & & \\
\hline & & 1 & 0.015 & 2.2 & & & \\
\hline & & & & & 0.0015 & 667 & 2.824 \\
\hline & $\mathrm{UO}_{2}(\mathrm{AC}) \cdot 4 \mathrm{H}_{2} \mathrm{O}$ & 0 & 0 & & & & \\
\hline & & 2 & 0.02355 & 73.42 & & & \\
\hline & & 5 & 0.059 & 62.45 & & & \\
\hline & & 8 & 0.0945 & 48.65 & & & \\
\hline & & 10 & 0.118 & 45.24 & & & \\
\hline & & & & & 0.003 & 333 & 2.523 \\
\hline
\end{tabular}

Table 3: Stability constant of Metal ion-2MCP complex.

These results are also consistent with literature values obtained by potentiometric titration on related compounds (Figure 11).
That is, $2 \mathrm{MCP}-\mathrm{Na}<2 \mathrm{MCP}-\mathrm{Al}<2 \mathrm{MCP}-\mathrm{U}<2 \mathrm{MCP}-\mathrm{Ce}<2 \mathrm{MCP}-\mathrm{Hg}$. The $2 \mathrm{MCP}-\mathrm{Hg}$ and $\mathrm{Ce}$ complexes are very strong. Those with $\mathrm{Na}$ are not stable. 


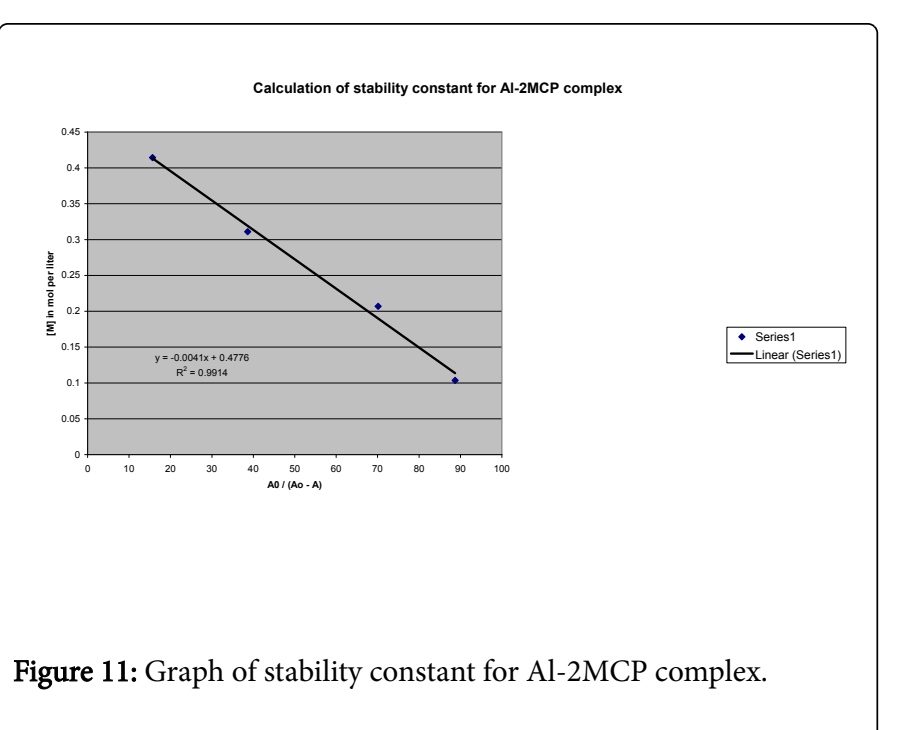

That implies that complexions with large stability constants are more stable than ones with smaller ones. Stability constants tend to be very large numbers. In order to simplify the numbers, a log scale is often used.

\section{Infrared and Raman spectra}

First the infrared or Raman spectra of metal-free $2 \mathrm{MCP}$ were recorded alone, second the infrared or Raman spectrum of $2 \mathrm{MCP}$ after interactions with selected metal ion was also recorded, and third, the two spectra were compared. If the two spectra are similar, there is no interaction; if the two spectra are different, there is interaction. Interpretation of infrared and Raman spectra is based on vibrational data found in the literature [13,21-26]. Also, the focus on certain spectra is based on conclusions obtained from the electronic spectra of this project.

\section{The infrared spectrum of metal-free $2 \mathrm{MCP}$}

To identify the peaks of the main functional groups, Figure 12 shows the infrared spectrum of metal-free $2 \mathrm{MCP}$ in the region $4000-600 \mathrm{~cm}^{-1}$. This spectrum reveals the characteristic vibration bands of 2MCP. In the literature, the band at $1602 \mathrm{~cm}^{-1}$ is attributed to $\mathrm{v}(\mathrm{N}-\mathrm{H})$, those at $1215 \mathrm{~cm}^{-1}$ and $1182 \mathrm{~cm}^{-1}$ are attributed to $\mathrm{v}(\mathrm{C}=\mathrm{S})$ and $\beta(\mathrm{C}=\mathrm{S})$ vibrations $[11,13]$. Because intermolecular interactions are expected to occur, it is likely that hydrogen bonds were developed. That explains the broadband at around $2500 \mathrm{~cm}^{-1}$. All the above bands are typical of the thione structure. The peaks at around $979 \mathrm{~cm}^{-1}$ and $959 \mathrm{~cm}^{-1}$ are due to $\mathrm{N}-\mathrm{H}$ stretching. The rest of the bands are associated with methyl groups and aromatic ring vibrations. Thus, the infrared spectra provide experimental evidence that the throne is the dominant form, in agreement with the literature [10].

The band at $1602 \mathrm{~cm}^{-1}, 979 \mathrm{~cm}^{-1}$, and $959 \mathrm{~cm}^{-1}$ are due to N-H group. The bands at $1215 \mathrm{~cm}^{-1}$ and $1182 \mathrm{~cm}^{-1}$ are due to $\mathrm{C}=\mathrm{S}$ group. Interactions of $2 \mathrm{MCP}$ with metal ions will change the frequencies or intensities of these bands.

\section{Effect of $\mathrm{pH}$ on the infrared spectra of metal-free 2-mercapto pyrimidine}

The importance of $\mathrm{pH}$ : There is a significant effect of $\mathrm{pH}$ on the structure of $2 \mathrm{MCP}$. Figure 13 shows the infrared spectra of $2 \mathrm{MCP}$

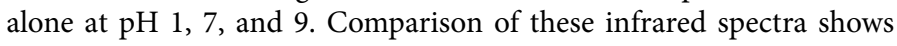
that $\mathrm{pH}$ has an effect on the peak intensities of $2 \mathrm{MCP}$. Our reference is the spectrum of $2 \mathrm{MCP}$ at $\mathrm{pH}$ 7. The intensities of the peak due to $\mathrm{N}-\mathrm{H}$ at $979 \mathrm{~cm}^{-1}$ and $959 \mathrm{~cm}^{-1}$ are of equal intensity.

When the $\mathrm{pH}$ was increased to 9 , the peak at $959 \mathrm{~cm}^{-1}$ decreases in intensity. All the other bands remain unchanged, that is deprotonation.

When the $\mathrm{pH}$ is adjusted to 2 , the peak at $959 \mathrm{~cm}^{-1}$ increases in intensity. All the other bands remain unchanged (i.e., Protonation).

The structure of $2 \mathrm{MCP}$ is affected by the change in $\mathrm{pH}$ at the level of the $\mathrm{N}$ atom. An acidic solution induces protonation of $2 \mathrm{MCP}$ and an alkaline solution induces deprotonation of 2MCP. These results are consistent with those obtained using electronic spectra.

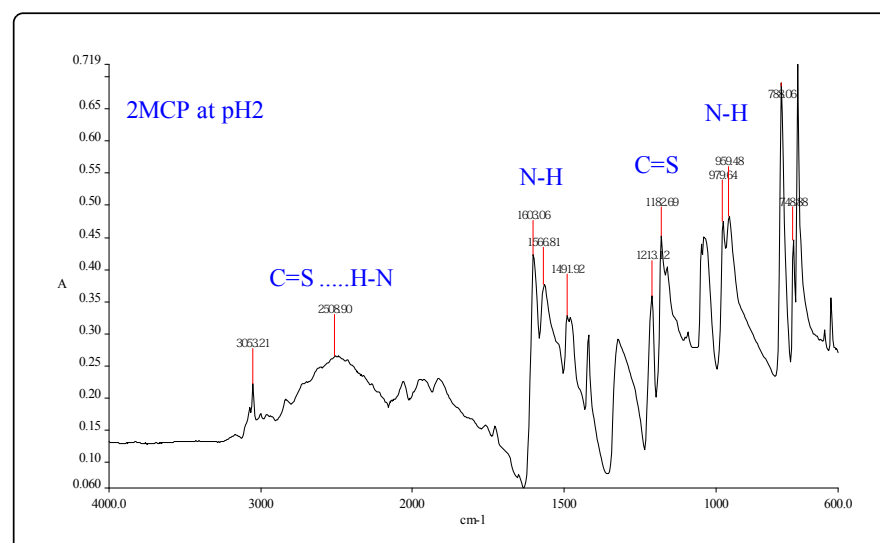

Figure 12: Infrared Spectra of 2-Mercaptopyrimidine.

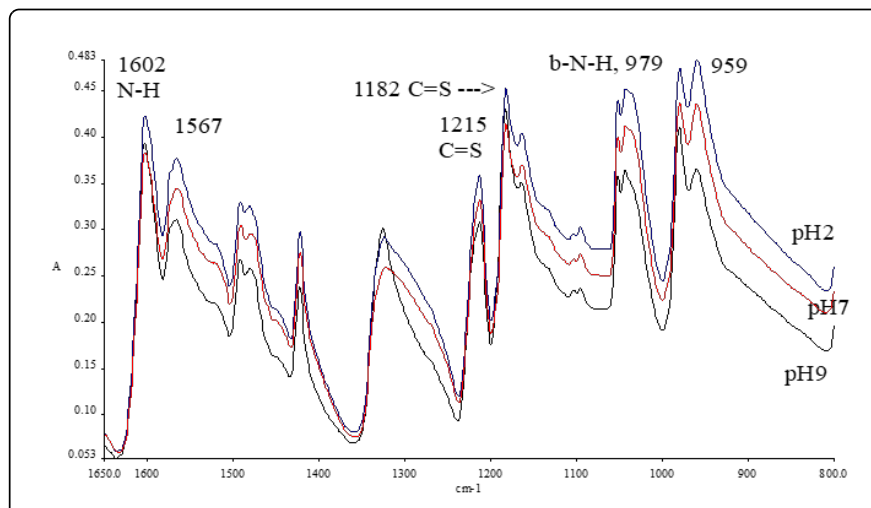

Figure 13: $\mathrm{pH}$ effect on $2 \mathrm{MCP}$ structure: An Infrared spectrum has changed the structure of $2 \mathrm{MCP}$ leading to protonation and deprotonation of the compound at $\mathrm{pH} 2,7$ and 9 respectively.

\section{Effect of complexation on the infrared spectra of 2- Mercaptopyrimidine (goal \#3)}

To identify the preferred binding sites of metal ions on $2 \mathrm{MCP}$ monitoring the change in peak position (frequencies) or in peak intensity indicated the complexation of $2 \mathrm{MCP}$ by metal ion [13]. 
$\mathrm{Hg}$ and $\mathrm{Ce}$ ions: Figures 14 and 15 show the infrared spectra of $2 \mathrm{MCP}$ interacting with $\mathrm{Hg}$ (II) and Ce (IV) [22,27]. The bands due to $\mathrm{N}-\mathrm{H}$ groups are shifted to lower wave numbers (frequencies) upon complex formation. This confirmed that the $\mathrm{N}$ atom of $\mathrm{N}-\mathrm{H}$ group coordinates to $\mathrm{Hg}$ (II) and $\mathrm{Ce}$ (IV). The shifting to the lower frequencies can be explained as a weakening of the $\mathrm{N}-\mathrm{H}$ bond resulting from the electron density drainage from the $\mathrm{N}$ atom due to its coordination to the metal atom. The most dramatic changes appear for the $\mathrm{C}=\mathrm{S}$ group, the bands are due $\mathrm{C}=\mathrm{S}$ disappear or are largely shifted towards lower wave numbers for $\mathrm{Hg}$ (II) and Ce (IV). This confirms that the $\mathrm{S}$ atom of the $\mathrm{C}=\mathrm{S}$ group coordinates to $\mathrm{Hg}$ (II) or Ce (IV). The shifting to the lower frequencies can be explained as a weakening of the $\mathrm{C}=\mathrm{S}$ bond resulting from the electron density drainage from the $\mathrm{S}$ atom due to its coordination to the metal atom.

The preferred binding site of the metal ion is better evidenced by infrared spectroscopy than by electronic spectroscopy. Both N and Scoordination are suggested in these cases.

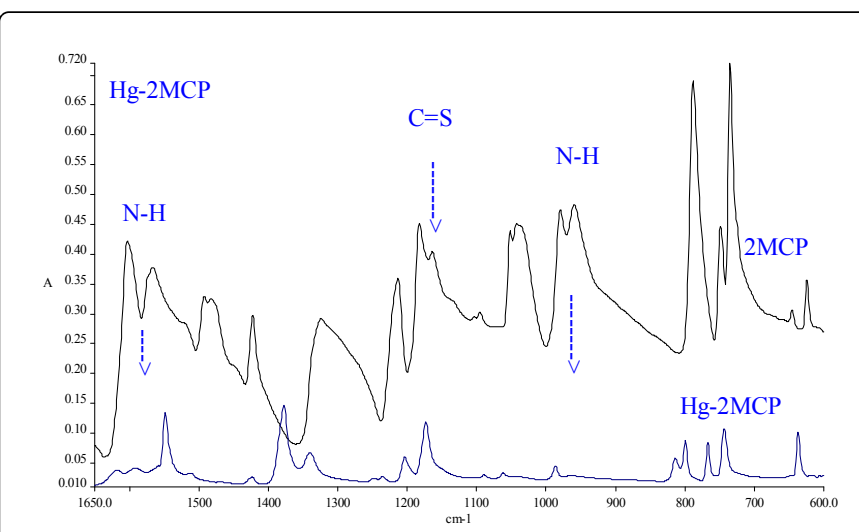

Figure 14: Infrared spectra of $2 \mathrm{MCP}$ and its $\mathrm{Hg}$ (II) complex.

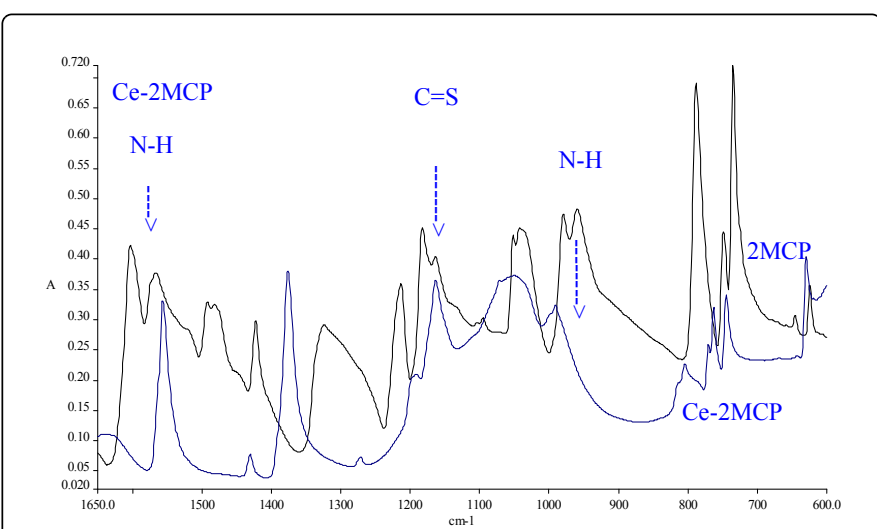

Figure 15: Infrared spectra of $2 \mathrm{MCP}$ and its Ce (IV) complex.

Aluminum ions: Figure 16 shows the infrared spectra of $2 \mathrm{MCP}$ interacting with $\mathrm{Al}$ (III). There is a significant change in the infrared spectra. The intensity of the band at $1602 \mathrm{~cm}^{-1}$ and $959 \mathrm{~cm}^{-1}$ due to $\mathrm{N}$ $\mathrm{H}$ is decreased upon complex formation. The band at $1212 \mathrm{~cm}^{-1}$ is also shifted. This confirms that interaction between $2 \mathrm{MCP}$ and $\mathrm{Al}$ comes through the $\mathrm{N}$ atom of the $\mathrm{N}-\mathrm{H}$ group and the $\mathrm{S}$ atom of the $\mathrm{C}=\mathrm{S}$ group.

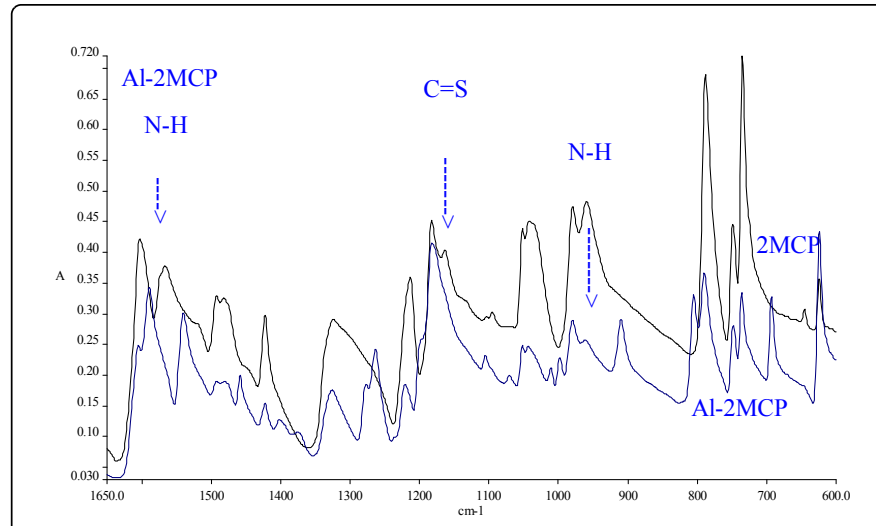

Figure 16: Infrared spectra of $2 \mathrm{MCP}$ and its $\mathrm{Al}$ (III) complex.

There is a significant interaction between $2 \mathrm{MCP}$ and $\mathrm{Al}$ ions. These results are not in agreement with the electronic spectra.

$\mathrm{Na}$ and Uranyl ions: Figures 17 and 18 show the infrared spectra of $2 \mathrm{MCP}$ interacting with $\mathrm{Na}^{+}$and uranyl respectively $[13,27]$. There is no dramatic change in the infrared spectra. Only the intensity of the band at $959 \mathrm{~cm}^{-1}$ due to $\mathrm{N}-\mathrm{H}$ is decreased on the formation of the complexes. This confirms that interaction between $2 \mathrm{MCP}$ and $\mathrm{Na}^{+}$, or uranyl comes through the $\mathrm{N}$ atom of $\mathrm{N}-\mathrm{H}$ group.

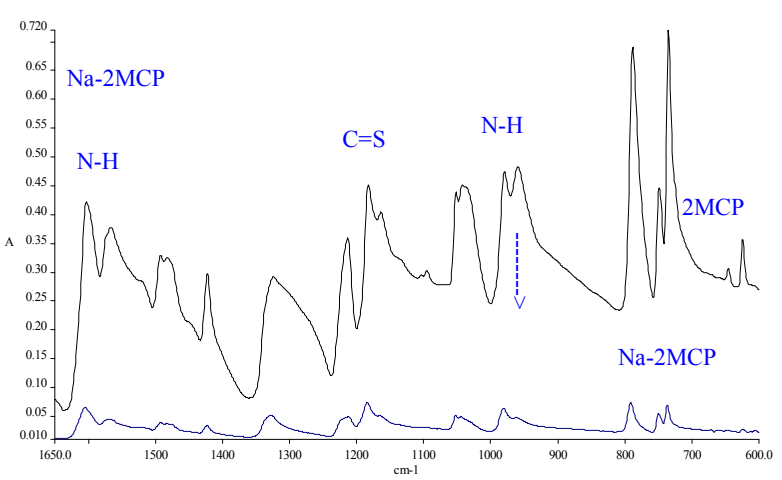

Figure 17: Infrared spectra of $2 \mathrm{MCP}$ and its $\mathrm{Na}$ (I) complex.

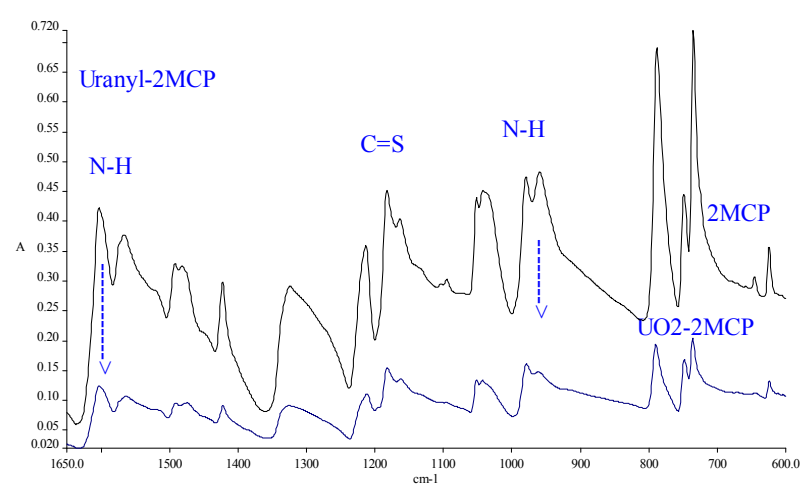

Figure 18: Infrared spectra of $2 \mathrm{MCP}$ and its $\mathrm{U}(\mathrm{VI})$ complex. 
There is a weak interaction between $2 \mathrm{MCP}$ and $\mathrm{Na}$, and uranyl ions. These results are in agreement with the electronic spectra.

\section{Effect of complexation on the Raman spectra of 2- Mercaptopyrimidine (goal \#3)}

To identify the possible covalent bonds between metal ions and 2MCP Raman spectroscopy has been used extensively for the study of active sites of metalloproteins. Structural and bonding information has been gained especially because the metal-ligand vibrations are found below $1000 \mathrm{~cm}^{-1}$ in the Raman spectra. Typically, the Raman spectrum of the metal/2MCP complexes displayed additional peaks (compared to the metal-free $2 \mathrm{MCP}$ Raman spectrum) in this region upon metal complexation. The peak at low frequency is characteristic of metal-2MCP interaction. In other words, the additional bands in the lower frequencies are due to the bonding between the metals and nonmetals [13]. From the results obtained using UV-visible and infrared spectra, the structure of metal ion/2MCP complexes was further studied by identifying the possible bonds formed between metal ions and the $\mathrm{N}$ and/or S atoms of 2MCP. Figure 19 shows the Raman spectra of $2 \mathrm{MCP}$ at different $\mathrm{pHs}$. The Raman spectra are similar to the infrared spectra, the main features remaining the same. Deprotonation of $2 \mathrm{MCP}$ is evidenced by an additional small band at around 1600 $\mathrm{cm}^{-1}$.

Hg ions: Figure 20 shows the Raman spectra of $2 \mathrm{MCP}$ with $\mathrm{Hg}$ (II). From the literature, and for related compounds, the band at $334 \mathrm{~cm}^{-1}$ was assigned to the bond $\mathrm{Hg}-\mathrm{S}$, and the band at $238 \mathrm{~cm}^{-1}$ was assigned to $\mathrm{Hg}-\mathrm{N}$. Hg (II) binds to both nitrogen and sulfur atoms of the $2 \mathrm{MCP}$ in a strong way [22]. Assignment of other bands requires the use of computation technique.

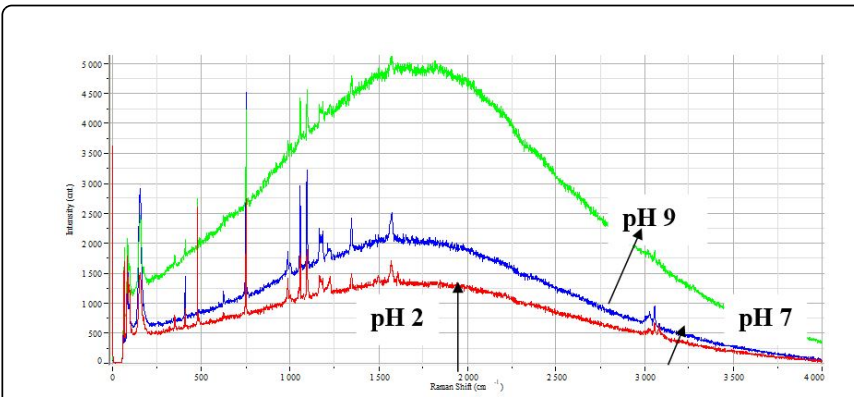

Figure 19: $\mathrm{pH}$ effect on $2 \mathrm{MCP}$ structure: Raman spectrum has changed the structure of $2 \mathrm{MCP}$ leading to protonation and deprotonation of the compound at $\mathrm{pH} 2,7$ and 9 respectively.

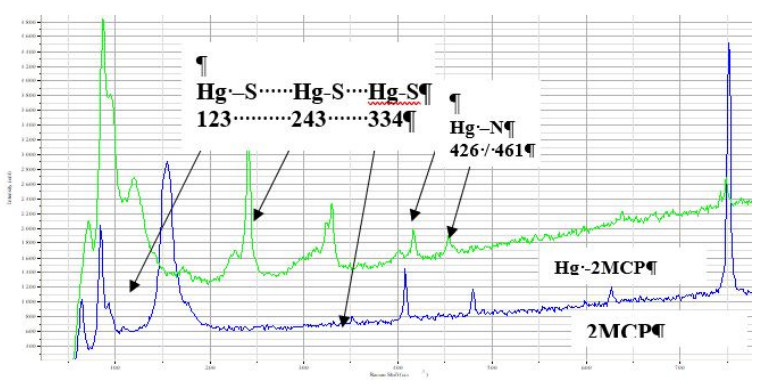

Figure 20: Raman spectra of $2 \mathrm{MCP}$ at its $\mathrm{Hg}$ (II) complex.
$\mathrm{Al}, \mathrm{Na}$, and Uranyl ions: Figure 21 shows the Raman spectrum between 2MCP with $\mathrm{Na}$ (I). Comparison of the Raman spectra of metal-free $2 \mathrm{MCP}$ and that of Na-2MCP complex shows no difference. This confirms that $\mathrm{Na}$ (I) does not interact in a significant way with either the sulfur or the nitrogen atom of the 2MCP. UV visible and infrared technique show a weak interaction through the $\mathrm{N}$ atom, but this interaction is definitely very weak, in agreement with the calculated stability constant.

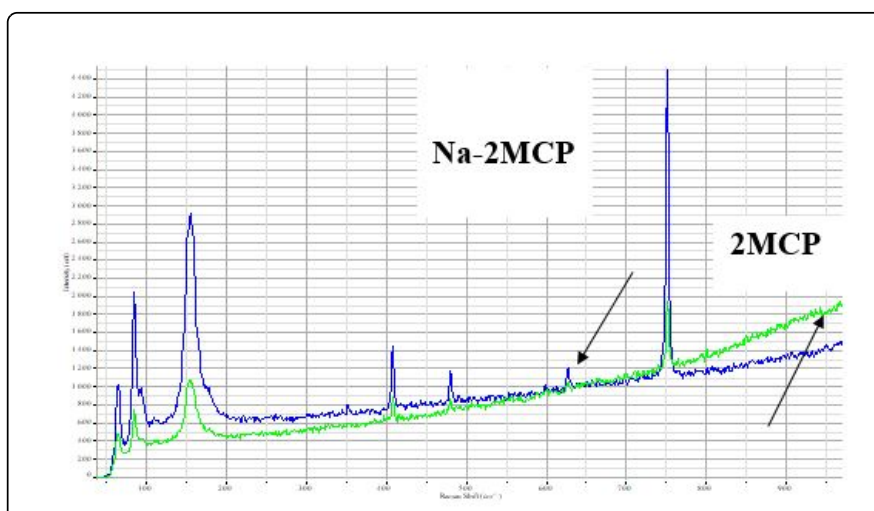

Figure 21: Raman spectra of $2 \mathrm{MCP}$ and its $\mathrm{Na}$ (I) complex.

Figure 22 shows the Raman spectra of $2 \mathrm{MCP}$ with $\mathrm{Al}$ (III). From the literature, and for related compounds, the strong band at $138 \mathrm{~cm}^{-1}$ was assigned to the bond $\mathrm{Al}-\mathrm{N}$. Al (III) binds strongly to the $\mathrm{N}$ atom of the 2MCP. A weak band at around $330 \mathrm{~cm}^{-1}$ is the Al-S bond. Assignment of other bands requires the use of computational techniques.

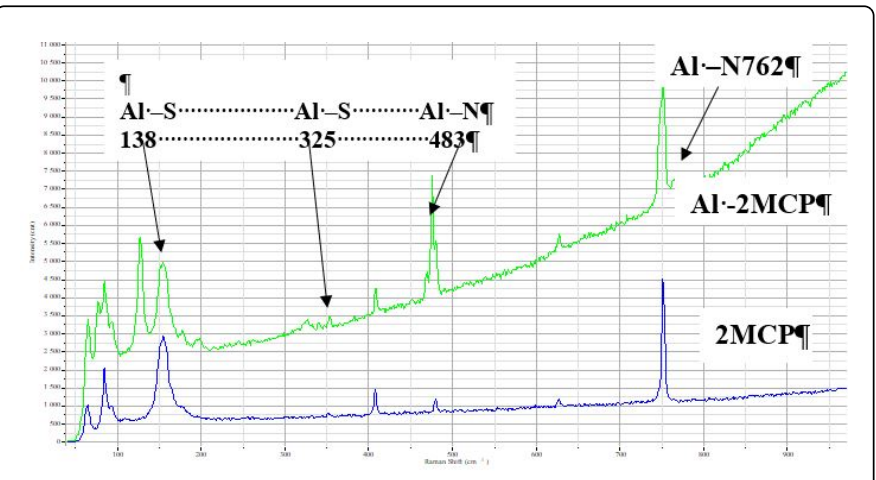

Figure 22: Raman spectra of $2 \mathrm{MCP}$ and its $\mathrm{Al}$ (III) complex.

The result of the Raman spectra shows Hg (II) binds to both sulfur and nitrogen. $\mathrm{Al}$ (III) binds to nitrogen and, in a weaker way, to $\mathrm{S} . \mathrm{Na}$ (I) does not bond to $2 \mathrm{MCP}$ in any significant way.

\section{Discussion}

\section{Electronic spectra}

In the first phase of this study, the UV-visible spectra of $2 \mathrm{MCP}$ and its complexes were examined at different $\mathrm{pHs}$ and metal ion/ligand molar ratios. $2 \mathrm{MCP}$ is strongly affected by changes in $\mathrm{pH}$. In acidic solution, $2 \mathrm{MCP}$ is protonated through the lone pair of the $\mathrm{N}$ atom. From this result, we can predict that $\mathrm{H}+$ and the metal ion $\mathrm{Mn}^{+}$will compete for the same binding site in an acidic solution. The 
Page 10 of 11

protonation and deprotonation of $2 \mathrm{MCP}$ disturbed the aromatic ring so protonation induced a shift to higher wavelength while deprotonation induced a shift to lower wavelength (blue shift) [13].

Among the metal ions used in this study, $\mathrm{Hg}$ and Ce have been shown to bind more strongly to $2 \mathrm{MCP}$. The explanation may lie in the structure of these ions. They possess d orbital that is empty, so they use the empty orbital to coordinate to $\mathrm{N}$ or $\mathrm{S}$ atoms of $2 \mathrm{MCP}$. The case of uranyl is a little different because of the presence of $\mathrm{O}$ atoms near $\mathrm{U}$ atoms. The $\mathrm{O}$ atoms prevent $2 \mathrm{MCP}$ from binding to the $\mathrm{U}$ atom. The calculated stability constants agree with the conclusions drawn from the UV visible spectra.

\section{Infrared and Raman spectra}

In the second phase of this study, the infrared and Raman spectra of $2 \mathrm{MCP}$ and its complexes have been examined at different $\mathrm{pH}$ and metal ion/ligand molar ratios. $2 \mathrm{MCP}$ is seriously affected by changes in $\mathrm{pH}$. An acidic solution, $2 \mathrm{MCP}$ is protonated through the lone pair of the $\mathrm{N}$ atom, and in an alkaline solution, $2 \mathrm{MCP}$ is deprotonated. Protonation or deprotonation of $\mathrm{N}-\mathrm{H}$ has the consequence the weakening the band so the infrared band due to N-H groups are shifted to lower frequencies (wave number) in acidic solution. The same is true when metal ion coordinates to $\mathrm{N}-\mathrm{H}$. The shifting to lower frequencies can be explained as a weakening of the N-H bond resulting from the electron density drainage from the $\mathrm{N}$ atom due to its coordination to the metal atom. The same explanation is valid when coordination occurs through the $\mathrm{S}$ atom. Every time the structure of a compound is changed there is a change in the force constant described by Hooks law, so the frequency will also change [12].

In the third and final phase of this study, structural and bonding information was gained especially because the metal-ligand vibrations are found below $1000 \mathrm{~cm}^{-1}$ in the Raman spectra. The metal ions are heavier than the other atoms so when you consider Hook's law, the reduced mass is greater, so the frequency is lower because the frequency is inversely proportional to the square root of the reduced mass. Typically, the Raman spectrum of the metal/2MCP complexes displays an additional peak (compared to the metal-free 2MCP Raman spectrum) in this region upon metal complexation. This peak at low frequency is characteristic of metal-2MCP interaction.

\section{Conclusion}

Interactions between $2 \mathrm{MCP}$ and 5 different metal ions have been extensively studied using UV visible, infrared and Raman spectra:

\section{- Effect of UV-visible spectra on 2MCP}

Electronic spectra have shown that (1) $\mathrm{pH}$ affects the structure of 2MCP, (2) the thione form is the dominant species in water, and (3) all the metal ions cited above interact with 2-MCP. But $\mathrm{Hg}$ (II) and Ce (IV) interact with the $2 \mathrm{MCP}$ more strongly than $\mathrm{Na}$ (I), $\mathrm{Al}$ (III), and $\mathrm{UO}^{22+}$. The stability constants calculated using electronic spectra and a Scatchard plot demonstrated that the complexes of $\mathrm{Hg}$ and Ce with 2MCP are the most stable.

\section{- Effect of Infrared and Raman spectra on 2MCP}

Infrared and Raman spectra have shown some marker bands useful to identify the sites involved in metal chelation at a specific $\mathrm{pH}$ value. Particularly the preferred binding sites on $2 \mathrm{MCP}$ are $\mathrm{S}$ and $\mathrm{N}$ atoms for $\mathrm{Hg}$ and $\mathrm{Ce}$, and only $\mathrm{N}$ atom for $\mathrm{Al}, \mathrm{Na}$, and $\mathrm{U} . \mathrm{Hg}, \mathrm{Ce}$, and $\mathrm{Al}$ ions form covalent bonds with $2 \mathrm{MCP}$. Infrared and Raman spectroscopies are powerful tools for investigating the preferred binding sites of the metal ions on a molecule. All coordinate bonds are covalent in nature.

\section{References}

1. Sahni SK, Reedijk J (1984) Coordination chemistry of chelating resins and ion exchangers. Coord Chem Rev 59: 1-139.

2. Joachim G, Jones LJ, Jones SJ (2001) Role of Iron in Estrogen-Induced Cancer. Current Medicinal Chemistry 8: 839-849.

3. Cui Z, Lockman PR, Atwood CS, Hsu C, Gupte A, et al. (2005) Novel Dpenicillamine carrying nanoparticles for metal chelation therapy in Alzheimer's and other CNS diseases. European Journal of Pharmaceutics and Biopharmaceutics 59: 263-272.

4. Turel I (2002) The interactions of metal ions with quinolone antibacterial agents. Coord Chem Rev 232: 27-47.

5. Akrivos PD (2001) Recent studies in the coordination chemistry of heterocyclic thiones and thionates. Coordination Chemistry Reviews 213: 181-210.

6. Raper ES (1996) Complexes of heterocyclic thionates. Part I. Complexes of monodentate and chelating ligands. Coordination Chemistry Reviews 153: 199-255.

7. Khan BT, Bhatt J, Najmuddin K, Shamsuddin S, Annapoorna K (1991) Synthesis, Antimicrobial, and Antitumor activity of a series of palladium (II) mixed ligand complexes. Journal of Inorganic Biochemistry 44: 55-63.

8. Calzon JAG, Alvarez JL, Fonseca JML (2005) Oxidation process induced by 2 -Mercaptopyrimidine at a mercury electrode. Journal of Colloid and Interface Science 290: 498-504.

9. Izquierdo JL, Guiteras BJ (1998) Thermodynamic properties of 2Mercaptopyridine and 2- Thiobarbituric acid. Thermochimica Acta 127: 81-88.

10. Martos-Calvente R, de la Penne-O'Shea VA, Campos-Martin JM, Fierro JLG (2003) The usefulness of density functional theory to describe the tautomeric equilibrium of 4, 6-Dimethyl-2-Mercaptopyrimidine in solution. J Phys Chem 107: 7490-7495.

11. Nowak MJ, Rostkowska H, Lapinski L, Leszczynski J, Kwiatkowski JS (1991) Infrared experimental and ab initio quantum mechanical studies of 2-Mercaptopyrimidine tautomers. Spectrochemical Acta 47: 339-353.

12. Silverstone RM, Clayton BG, Terence CM (1991) Spectroscopic Identification of Organic Compounds. In: Ultraviolet Spectrometry. John Wiley \& Sons, New York, pp: 289-315.

13. Nakamoto K (1977) Infrared and Raman Spectra of Inorganic and Coordination Compounds. Wiley \& Sons. New York.

14. Ramachandran B, Joseph RL, Chris DG (2005) Enhanced Fluorescence Cyanide Detection at Physiologically Lethal Levels: Reduced ICT-Based Signal Transduction. Journal American Chemical Society 127: 3635-3641.

15. Chunlin M, Guangru T, Rufen Z (2006) New triorganotin (IV) complexes of polyfunctional S, N, O-ligands: Supramolecular structures based on and/or C-H interactions. Journal of Organometallic Chemistry 691: 2014-2022.

16. Krishna Kumar V, John Xavier R (2006) Molecular and vibrational structure of 2-mercapto pyrimidine and 2, 4-diamino-6-hydroxy-5nitroso pyrimidine: FT- IR, FT-Raman and quantum chemical calculations. Spectrochimica Acta, Part A: Molecular and Biomolecular Spectroscopy 63: 454-463.

17. Koos M, Novotna Z, Rybar A (1994) Influence of structure on antimicrobial activity of some heterocycles. III. 1-Substituted 2-methyl-5nitroimidazoles. Chemical Papers 48: 50-54.

18. Khan BT, Bhatt J, Najmuddin K, Shamsuddin S, Annapoorna K (1991) Synthesis, antimicrobial, and antitumor activity of a series of palladium(II) mixed ligand complexes. Journal of Inorganic Biochemistry 44: 55-63.

19. Khan MMT, Chatterjee D, Hussain A, Moiz MA (1990) Kinetics, and mechanism of the ligand substitution reaction of an aquoethylenediaminetetraacetato complex of ruthenium (III) with 4,6- 
Citation: Kamara B, Kamara HM, Phambu N (2018) pH-Dependent lon Binding Studies on 2-Mercaptopyrimidine. J Environ Anal Chem 5: 245. doi:10.4172/2380-2391.1000245

Page 11 of 11

dimethyl-2- mercapto pyrimidine ligand in an aqueous medium Polyhedron 9: 2681-2687.

20. Harris DC (2003) Quantitative Chemical Analysis. 6th edn. W H Freeman and Company, New York, USA.

21. Perez-Quintanilla D, del-Hierro I, Fajardo M, Sierra I (2006) Adsorption of cadmium (II) from aqueous media onto a mesoporous silica chemically modified with 2- mercaptopyrimidine. Journal of Materials Chemistry 16: 1757-1764.

22. Guillermo CJ, Seguel GV, Alderete JB (1994) The vibrational spectra of some 2- mercapto pyrimidine complexes of mercury (II). Spectrochimica Acta Part A: Molecular and Biomolecular Spectroscopy 50: 371-374.

23. Khan BT, Bhatt J, Najmuddin K, Shamsuddin S, Annapoorna K (1991) Synthesis, antimicrobial, and antitumor activity of a series of palladium(II) mixed ligand complexes. Journal of Inorganic Biochemistry 44: 55-63.
24. Nowak MJ, Rostkowska H, Lapinski L, Leszczynski J, Kwiatkowski JS (1991) Infrared experimental and ab initio quantum mechanical studies of 2- mercapto pyrimidine tautomers. Spectrochimica Acta, Part A: Molecular and Biomolecular Spectroscopy 47: 339-353.

25. Zhou J, Xiwen H (1999) Study of the nature of recognition in molecularly imprinted polymer selective for 2-aminopyridine. Analytica Chimica Acta 381: 85-91.

26. Kang SW, Chang CW, Suh MY, Lee DY, Choi WJ (1992) Studies on the electrochemical behavior of heavy lanthanide ions and the synthesis, characterization of heavy metal chelate complexes (II). Synthesis and characterization of eight coordinate tungsten (IV) and cerium (IV) chelate complex. Analytical Science and Technology 5: 41-49.

27. Rose D, Yuan-Da C, Chen Q, Zubieta J (1994) Reactions of Uranyl Thiolate Complexes with Molecular Oxygen: Syntheses and Crystal and Molecular Structures of the Uranyl Thiolate Peroxo Species. 